\title{
Can we Continue to Afford Access to Cancer Treatment?
}

\author{
Nils Wilking, ${ }^{1}$ Gilberto Lopes, ${ }^{2}$ Klaus Meier, ${ }^{3}$ Steven Simoens ${ }^{4}$ Wim van Harten ${ }^{5,6}$ and Arnold Vulto7
}

1. Karolinska Institutet, Solna, Sweden; 2. Sylvester Comprehensive Cancer Center, University of Miami, FL, US; 3. HKK Soltau, Lower Saxony \& Heidekreis-Klinikum GmbH, Soltau, Germany; 4. KU Leuven, Leuven, Belgium; 5. University Twente, Enschede, The Netherlands; 6. Rijnstate Hospital, Arnhem, The Netherlands; 7. Erasmus University Medical Center, Rotterdam, The Netherlands

$\mathrm{O}$ ncology is facing a crisis of affordability that is not sustainable. The economic burden of cancer is growing, as a result of the rising cancer incidence and increased survival, alongside growing investment in disease prevention, diagnosis and treatment. The prices of new cancer drugs continue to increase, placing growing pressure on many healthcare systems. The aim of this article is to explore the reasons why the cost of cancer care is increasing, and why this increase may become unsustainable unless changes are made. There are only limited options for future health spending. Finding ways to improve the allocation of existing resources to achieve the best outcomes for patients will be key to achieving sustainability, whilst safeguarding the continued development of new, effective cancer treatments. Currently, too many cancer drugs are approved without robust evidence of value, and spending more on treatments does not necessarily translate to improvements in health. For all new drugs, in addition to efficacy and safety, there should be a focus on value, with measured outcomes and pricing that ensures these drugs are affordable. Fundamental changes to healthcare systems and industry are needed to sustain cancer care and allow continued access to effective and safe treatments for all patients.

\section{Keywords}

Sustainability, cancer care, value, outcome, affordability, healthcare

Disclosure: Nils Wilking, Gilberto Lopes, Klaus Meier, Steven Simoens and Wim van Harten have nothing to disclose in relation to this article. Arnold Vulto has nothing to disclose in relation to this article and no financial interest in any pharmaceutical company. His institution receives financial compensation for consulting/lecturing activities on behalf of AbbVie, Amgen, Biogen, Boehringer Ingelheim, EGA (Medicines for Europe), Mundipharma, Pfizer/Hospira, Roche and Novartis/Sandoz/Hexal.

Acknowledgements: Editorial assistance was provided by Sarah Stutfield, PhD, of Spirit Medical Communications Ltd., funded by Sandoz International $\mathrm{GmbH}$.

Compliance with Ethics: This study involves a review of the literature and did not involve any studies with human or animal subjects performed by any of the authors.

Authorship: All named authors meet the International Committee of Medical Journal Editors (ICMJE) criteria for authorship of this manuscript, take responsibility for the integrity of the work as a whole, and have given final approval to the version to be published.

Open Access: This article is published under the Creative Commons Attribution Noncommercial License, which permits any non-commercial use distribution, adaptation and reproduction provided the original author(s) and source are given appropriate credit.

Received: 8 June 2017

Accepted: 7 August 2017

Citation: European Oncology \& Haematology, 2017;13(2):114-9

Corresponding Author: Nils Wilking, Department of Oncology and Radiation Physics, Skåne University Hospital, Lund/Malmö, Department of OncologyPathology, Karolinska Institutet, Stockholm, Sweden. E: nils.wilking@skane.se

Support: The publication of this article was supported by Sandoz International $\mathrm{GmbH}$. The views and opinions expressed are those of the author and do not necessarily reflect those of Sandoz International GmbH.
Innovation in healthcare is highly beneficial from a patient perspective; however, the introduction of new drugs, often at high cost, is placing increasing pressure on many healthcare systems. ${ }^{1}$ As a result, these systems are facing a growing crisis of affordability, both globally and locally, which is unsustainable. Oncology is the area of greatest concern. In Europe alone, cancer is a major cause of morbidity and mortality. ${ }^{2}$ In 2013, cancer represented $17 \%$ of the total burden of disease in Europe (as measured in disability adjusted life years [DALYS]), ${ }^{3}$ and caused the equivalent of 25 million years of healthy life lost due to ill-health, disability and death. ${ }^{4}$ According to the latest GLOBOCAN data, the estimated cancer incidence in Europe in 2012 was 3.4 million cases, 2,5 representing a $31 \%$ increase compared with $1995^{2}$ and this trend is expected to continue.

Cancer care consumes up to $30 \%$ of total hospital expenditure across Europe, ${ }^{6}$ and spending on cancer treatment has risen faster than spending in many other areas of healthcare, with costs continuing to rise considerably. ${ }^{7.8}$ However, despite this, the share of healthcare expenditure allocated to cancer remains significantly lower than the share of the cancer disease burden (Figure 1). ${ }^{3}$

The increasing economic burden of cancer is closely linked to rising cancer incidence, and increased survival, alongside growing investment in disease prevention, diagnosis and treatment. ${ }^{2}$ It is estimated that new, cancer drugs have accounted for $50-60 \%$ of the increase in cancer survival rates since 1975, ${ }^{\circ}$ but at an increasing cost. In Europe, total cancer drug sales more than doubled between 2005 and 2014, increasing from $€ 8.0$ billion to $€ 19.8$ billion. ${ }^{2}$ These rising costs are due to the rising prices of newly approved drugs, the growing number of patients requiring treatment, and increased survival rates leading to higher cumulative treatment costs over a patient's lifetime.,2,10

In some countries, this increasing economic burden is placing physicians under significant pressure to balance the cost of cancer care with each testing and/or prescribing decision, which can lead to patients being 
denied access to effective treatments, or the use of treatments with limited cost-effectiveness. For example, in Brazil, trastuzumab is not generally available in public settings for the treatment of metastatic disease. It is estimated that of 2,008 women diagnosed with advanced HER2-positive breast cancer in 2016, only 808 will be alive by 2018 if they receive only chemotherapy (the treatment offered by the public health system), while 1,408 women will be alive if they receive chemotherapy plus trastuzumab. ${ }^{11}$

As a result of these growing economic pressures, healthcare decisionmakers are struggling to manage their funds and, at the same time, provide optimal treatment for individual patients. ${ }^{12}$ All patients have a right to receive the best care possible and if healthcare expenditure is insufficient or not sustained, this may impact significantly on the quality of all aspects of care, leading to a poorer patient prognosis. However, it should not be the sole responsibility of the payer, hospital pharmacist or physician to make economic decisions regarding cancer treatment; team collaboration is needed to perform a comprehensive assessment of the key factors and ensure that essential parameters are met.

A team of experts in medical oncology, hospital pharmacy and health economics from across Europe have come together to collate the current evidence on the sustainability of cancer care and the possible consequences if we reach the ceiling (i.e., limit) of sustainability within Europe. This information is presented in a series of reviews, in a way that is easily understandable and relevant to the general oncologist. In this first paper, we will address: (1) the reasons why costs are increasing, and (2) why this may be unsustainable unless changes are made, while the second paper considers what could happen if changes are not made and we reach the ceiling of sustainability. ${ }^{13}$

\section{The cost of cancer drugs is a key component of rising healthcare costs}

The cost of cancer care in Europe rose from €35.7 billion in 1995 to $€ 83.2$ billion in 2014, and this increase is predicted to continue. ${ }^{14}$ These rising costs are driven by several factors, including the increasing incidence of cancer, resulting from a growing and ageing global population; a greater number of patients receiving treatment; the recent introduction of a large number of new, high-cost treatments; lengthening treatment durations; and the high cost of end-of-life care. ${ }^{15-18}$

Over the past 10 years, the number of oncology drugs in development has expanded by over 60\%.16 This number includes 70 new oncology treatments for over 20 different tumour types launched over the past 5 years. $^{16}$ The late-phase oncology pipeline currently comprises 270 biological agents, including 16 gene therapies, 86 new monoclonal antibodies and 15 biosimilars of existing monoclonal antibodies, ${ }^{16}$ and it is estimated that by 2020 there could potentially be over 100 new cancer drugs. The introduction of these new treatments could have a substantial cost impact (Table 1), ${ }^{19-21}$ and it is perhaps unsurprising that many healthcare systems are struggling to adapt to this rapid, complex and increasingly costly evolution of the oncology landscape.,16

\section{Why is the cost of cancer drugs so high?}

Cancer treatments that are new to the market are usually priced more highly compared with established therapies. ${ }^{22}$ The pricing of new drugs often seems to follow a formula, starting with the price of the most recent similar drug on the market and then placing a premium of 10-20\% above this figure for the new drug. ${ }^{23}$ It has also been suggested that "what the market will bear" may be a central pricing consideration for pharmaceutical companies, with prices remaining high even when
Figure 1: Total spend relative to disease burden by disease ${ }^{3}$

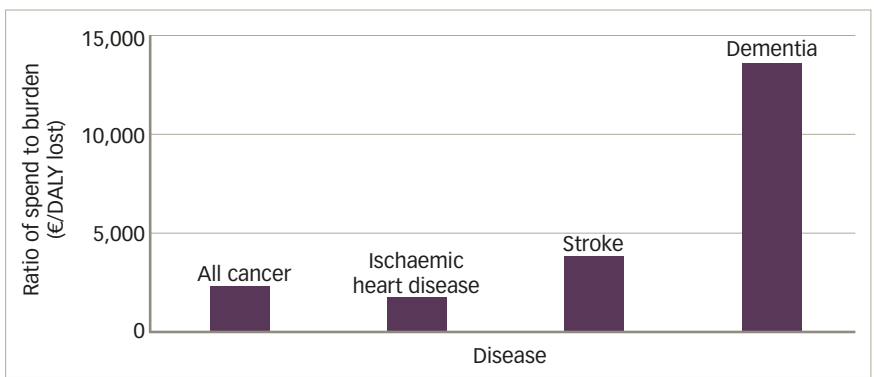

Data from 2013; average of 27 European countries. DALY = disability adjusted life year. Reproduced with permission from Cole et al., 2016. ${ }^{3}$

Table 1: 2019-2022 sales forecast for a selection of anticipated blockbuster oncology drugs, approved by the FDA in 2014-2016*19-21

\begin{tabular}{|c|c|}
\hline Drug & $\begin{array}{l}\text { Estimated annual sales in US\$ billions in } \\
\text { US and EU5 (5 largest EU markets)** }\end{array}$ \\
\hline FDA-approved $2014^{19}$ & Estimated annual sales 2019 (billion \$) \\
\hline Nivolumab & 5.3 \\
\hline Pembrolizumab & 3.3 \\
\hline Ramucirumab & 1.3 \\
\hline Siltuximab & 1.1 \\
\hline Idelalisib & 1.1 \\
\hline FDA-approved $2015^{20}$ & Estimated annual sales 2020 (billion \$) \\
\hline Palbociclib & 4.8 \\
\hline Daratumumab & 1.8 \\
\hline Elotuzumab & 1.4 \\
\hline Isaxomib & 1.2 \\
\hline Lenvatinib & 1.1 \\
\hline Osimertinib & 1.1 \\
\hline FDA-approved $2016^{21}$ & Estimated annual sales 2022 (billion \$) \\
\hline Atezolizumab & 4.2 \\
\hline Venetoclax & 2.6 \\
\hline
\end{tabular}

there is the potential for greater competition due to an increasing number of agents available..$^{24}$

The cost of bringing a new cancer drug to market is reportedly between $\$ 1$ billion and $\$ 2.6$ billion, ${ }^{23,25}$ which includes the cost of clinical development of the new successful drug plus all other drugs that failed during development, together with the cost of conducting the trials needed to gain approval and other ancillary expenses. ${ }^{23}$ However, this figure is widely debated and may be an overinflated estimate from industrysupported economists, based on potentially flawed methodology. Some independent experts put the figure as low as \$60-90 million and argue that public money is the major source of funding for R\&D. ${ }^{23.26}$ In support of this, evidence shows that public spending accounted for $57 \%$ of basic research in the United States in $2008 .^{27}$

Several studies have demonstrated a weak correlation between the price of a drug and its benefit for the individual patient in terms of prolonged survival, degree of tumour shrinkage, or improved quality of life (QoL). ${ }^{23,28,29}$ However, the nature of the disease and the seriousness of a diagnosis of cancer also means that physicians and patients are often willing to pay 
a high price for treatments, even those associated with only marginal improvements in outcome. ${ }^{30}$ Recent research suggests that market exclusivity for most approved tyrosine kinase inhibitors is more than a decade, averaging around 14-15 years. It could be argued that this is more than adequate time for pharmaceutical companies to recoup their investment costs and also make a fair profit, even allowing for the fact that not all of these compounds may be used for the full period of their market exclusivity, due to the approval of newer, more effective agents. ${ }^{31}$

The current system of funding R\&D clearly creates incentives to invest, and has been successful in bringing new, innovative cancer drugs to market. However, access to these drugs may be limited when a monopoly is granted (e.g., during the period of market exclusivity). If R\&D costs did not have to be recouped through high prices, drugs would be free of market exclusivity and could be made more widely available and priced more affordably.3. R\&D priorities should be driven by health needs rather than commercial potential, and governments need to develop new approaches to fund R\&D that will increase access to new drugs and improve their cost-effectiveness and affordability. This should include the implementation of policies that unlink R\&D costs from product prices, and the development of new ways of sharing the cost burden of innovation. . $^{32-34}$ In 2012, the WHO Consultative Expert Working Group on Research and Development proposed that all countries should commit to spend at least $0.01 \%$ of gross domestic product (GDP) on government-funded $R \& D$, but these targets are generally not being met by either developed or developing nations.$^{35}$ At the Seventieth World Health Assembly in 2017, a draft resolution proposed by 12 countries, including France and The Netherlands, recommended that a comprehensive technical report be prepared that examines pricing approaches and their impact on the availability and affordability of cancer medicines, including incentives for investment in R\&D in cancer and innovation, and financing gaps in R\&D. ${ }^{36}$

Generic drugs are widely used in oncology; however, the prices of many of these drugs are high compared with those for non-malignant diseases..$^{30}$ Furthermore, manipulation of generic drug prices has led to unwarranted price rises of some unbranded generic cancer drugs. For example, in 2013, the price of one pack of a generic busulfan, used to treat leukaemia, rose from $£ 5.20$ to $£ 65.22$ in England and Wales. ${ }^{37}$

Over the past decade, the number of orphan drug designations has roughly doubled, with a simultaneous increase in those that target biomarker-defined subsets of common diseases, most notably in oncology. ${ }^{38,39}$ Between 2009 and 2015, a total of 89 cancer drugs were approved for various indications, of which 39 (44\%) received orphan designation. Of these, 11 ( $28 \%$, or $12 \%$ of all newly approved cancer drugs) were for biomarker-derived disease subsets. For example, while non-small cell lung cancer (NSCLC) was once divided into squamous cell carcinoma and adenocarcinoma, it is now considered to be a heterogeneous disease. About $5 \%$ of NSCLCs have a rearrangement in the ALK gene, and three targeted therapies (crizotinib, ceritinib and alectinib) have been approved for treatment, with designated orphan drug status. Whether orphan drug status is associated with higher drug prices is a matter of debate. A recent study showed that the prices of cancer drugs did not differ substantially irrespective of whether the drug targeted a rare disease or a more common form of cancer. This suggests that there is no pricing premium for small patient populations but also no discount to reflect the smaller trials and generally shorter development times that are characteristic of drugs with orphan designation. ${ }^{39}$

Governments currently employ various approaches for ensuring the affordability of essential medicines. ${ }^{40}$ However, while cancer drugs are usually expensive, ${ }^{41}$ prices can also vary widely between countries. ${ }^{42}$ A comparison of publicly available costs of cancer drugs across 18 highincome countries including Europe, Australia and New Zealand found a variation of between $28 \%$ and $388 \%$ in the cost difference between the highest- and the lowest-priced country. ${ }^{42}$

In Europe, various reimbursement schemes are used by payers to increase patient access to new drugs, and these can be classified into financial-based schemes and performance/outcome-based schemes. ${ }^{43}$ Financial-based schemes include 'price per volume', which aims to control financial expenditure via refunds from the pharmaceutical company in cases of overbudget, and 'patient access schemes', which may involve pharmaceutical companies providing drugs either for free or at a discount, for an agreed period, to enhance the value of new drugs and increase the likelihood of funding or reimbursement. Performancebased schemes between pharmaceutical manufacturers and payers are those in which the price, level, or nature of reimbursement are linked to measures of endpoints related to survival or QoL, and the future performance of the product in either the clinical trial or realworld setting. These schemes often arise when a manufacturer has a high level of confidence in their product and is willing to accept a lower reimbursement level if it underperforms, and may be particularly relevant in markets where products are in close competition. ${ }^{44}$ However, there are concerns that such approaches may lead to limited transparency, because the agreed prices and the nature of these schemes are not usually disclosed to the public. As a result, policy makers risk overpaying when setting prices through external price referencing (i.e., official undiscounted prices). ${ }^{42}$

\section{The development of new and effective medicines must continue}

Given the continuing rise in treatments costs and increasing financial pressures on our healthcare systems coupled with the growing prevalence of cancer, finding ways to improve the appropriate allocation of existing resources to achieve the best possible outcomes for patients will be key to achieving sustainability. ${ }^{8}$

We may not be able to afford innovation in medical treatment in the future without new solutions. ${ }^{41}$ Nonetheless, there must remain a focus on developing new, effective medicines, given the magnitude of their potential benefit. New, targeted precision therapies have had a substantial impact on overall survival in some, but not all, tumour types (e.g., cancers defined by carcinogen-induced genomic chaos, such as ultraviolet-induced melanoma or tobacco-induced lung cancer, which are driven by a multitude of competing molecular pathways). ${ }^{45}$ For example, in gastrointestinal stromal tumours, the tyrosine kinase inhibitor, imatinib, is associated with an overall survival of almost 5 years compared with just $12-18$ months with chemotherapy (Table 2). ${ }^{46}$ However, with the introduction of these cancer treatments, prices and costs have risen sharply. This can present hurdles for access, meaning that patients in some countries are being denied the opportunity for the best treatment.

Policy guidelines all agree that cancer care should focus on improving survival and QoL. However, spending more on cancer drugs does not necessarily translate to improvements in health. ${ }^{1.47}$ Evidence shows that the relationship between a particular nation's spend on cancer care and outcomes is weak. For example, in some European countries, the cost of colorectal cancer varies almost 20-fold, with no clear evidence of a survival benefit (Figure 2), ${ }^{48}$ while others report highly variable outcomes for the same per-patient spend. ${ }^{49}$ 
Table 2: Impact of targeted therapies on overall survival in selected tumour types ${ }^{46}$

\begin{tabular}{|l|l|l|l|l|}
\hline Orphan disease & Old treatment & Old survival & $\begin{array}{l}\text { New } \\
\text { treatment }\end{array}$ & $\begin{array}{l}\text { New } \\
\text { survival }\end{array}$ \\
\hline $\begin{array}{l}\text { Acute promyelocytic } \\
\text { leukaemia }\end{array}$ & Chemotherapy & 19 months & $\begin{array}{l}\text { All-trans } \\
\text { retinoic acid }\end{array}$ & $\begin{array}{l}>58 \\
\text { months }\end{array}$ \\
\hline $\begin{array}{l}\text { Chronic myeloid } \\
\text { leukaemia }\end{array}$ & Chemotherapy & 6 years & Imatinib & $>22$ years \\
\hline Melanoma & Dacarbazine & $<10$ months & vemurafenib & 16 months \\
\hline $\begin{array}{l}\text { Medullary thyroid } \\
\text { cancer }\end{array}$ & Chemotherapy & 36 months & Vandetanib & $\begin{array}{l}\text { Not } \\
\text { reached }\end{array}$ \\
\hline $\begin{array}{l}\text { Gastrointestinal } \\
\text { stromal tumour }\end{array}$ & Chemotherapy & $\begin{array}{l}12-18 \\
\text { months }\end{array}$ & Imatinib & $\begin{array}{l}\text { Close to } \\
5 \text { years }\end{array}$ \\
\hline $\begin{array}{l}\text { Relapsed Hodgkin } \\
\text { lymphoma }\end{array}$ & Chemotherapy & 1.2 years & $\begin{array}{l}\text { Brentuximab } \\
\text { vedotin }\end{array}$ & $\begin{array}{l}22.4 \\
\text { months }\end{array}$ \\
\hline
\end{tabular}

Old survival = median overall survival with use of the old treatment; New survival = median overall survival with use of the new treatment. Reproduced with permission from Munoz and Kurzrock, 2012.46

\section{High drug costs should only be considered acceptable if improved patient outcomes can be demonstrated}

Currently, too many cancer drugs are being approved for use without robust evidence of added value, ${ }^{50}$ and clearer Health Technology Assessment (HTA)-based guidance is needed. For example, in 2015, several drugs were approved to treat various malignancies, despite an unfavourable harm-benefit balance. These included drugs that inhibit angiogenesis and tumour growth, such as cabozantinib for the treatment of medullary thyroid cancer..$^{51}$ There is currently no regulatory requirement to demonstrate a minimum or reasonable magnitude of benefit. Drugs are approved based on evidence of clinical benefit and safety, with no clear threshold for magnitude of benefit to justify their approval or cost. With a large enough sample size, a statistically significant increase in overall survival can be demonstrated, even if this correlates with an increased survival of only a few days or weeks. Drugs can also be approved based on surrogate endpoints, with no evidence that patients will benefit from improved QoL or survival.

A simple method has been developed for screening and scoring cost versus survival for cancer drugs used as first-line treatment for metastatic breast cancer and NSCLC. This approach assigns a percentage score that corresponds to cost per survival per day adjusted for efficacy, safety and QoL. ${ }^{52}$ Using a modification of this method adapted to the Italian economic situation, an assessment of six recently approved cancer drugs showed that the pricing of most of these medications was not appropriate, compared to their therapeutic value. None of the drugs evaluated (abiraterone, afatinib, aflibercept, bevacizumab, dabrafenib, and ipilimumab) achieved a final score of 75 (corresponding to adequate pricing), with afatinib achieving the highest score of 55 points. ${ }^{29}$

The absolute cost to society will become increasingly unaffordable if every drug with statistically significant, but clinically unimportant, benefit is approved and will be prescribed/reimbursed. ${ }^{30}$ For all new medicines, in addition to efficacy and safety, there should be a focus on value, with measured outcomes.

\section{Achieving greater value in cancer care}

Achieving high value for patients should be the overarching goal of healthcare delivery and value, defined as outcome relative to cost, ${ }^{53}$ is now a key topic in any debate regarding cancer care. ${ }^{54}$ Measuring value in cancer is challenging, and should take into account multiple
Figure 2: Total colorectal cancer expenditure* versus 5-year survival across European countries in 2006-200748

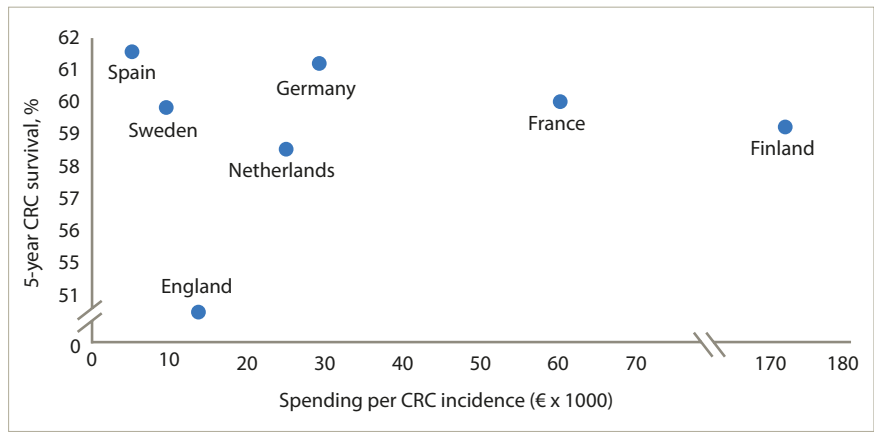

*Total colorectal cancer expenditure corrected for colorectal cancer incidence in selected countries. $C R C=$ colorectal cancer.

variables, including the natural history of the cancer type and patient factors. Traditionally, quality adjusted life years (QALYS) and incremental cost-effectiveness ratios (ICERS) have served as surrogate markers for value, although this approach fails to incorporate the viewpoints of all key stakeholders (i.e., patients, payers, providers, the public and policymakers). ${ }^{55}$ The European Society of Medical Oncology (ESMO) and American Society of Clinical Oncology (ASCO) have developed tools to evaluate the clinical utility of oncology drugs and assess their relative value ${ }^{56,57}$ (discussed further in the second paper in this series ${ }^{13}$ ). The ESMO Magnitude of Clinical Benefit Scale (ESMO-MCBS) is a wellvalidated tool to stratify the magnitude of clinical benefit for new cancer treatments, and can be applied to all solid tumours. ${ }^{56}$ The ASCO value of Cancer Care Task Force has provided a list of recommended targets for meaningful clinical trial goals. A hazard ratio of $\leq 0.8$, corresponding to an improvement in median overall survival within the range of 2.5-6 months, has been identified as the minimum incremental improvement over standard therapy that would define a clinically meaningful outcome. ${ }^{58}$

These instruments provide effective frameworks for the value-based pricing of cancer drugs, in which the price of new agents is based on the medical benefit that they offer to patients. However, measuring value is complex and even modest differences in the assumptions made when using the model can lead to substantial differences in estimates of costeffectiveness for a particular treatment. Value-based pricing fails to take into account the 'bigger picture', e.g., the long-term nature of treatment, the need for multiple drugs, and subjective aspects of value that cannot easily be measured, and does not consider different populations and what they can afford.99,60 Furthermore, it is counter to free-market principles and the setting of prices based on supply and demand. ${ }^{30}$ The WHO has also recently expressed reservations about the concept of value-based pricing, and instead supports a move towards the fair pricing of medicines. ${ }^{59}$

The balance between cost and relative value of new cancer treatments has stimulated broader discussion regarding appropriate resource allocation in healthcare. ${ }^{61}$ To weigh up the demand for new treatments with the financial impact of their introduction, other value-based solutions are needed to ensure equitable access to treatment. ${ }^{54}$ Policy makers require guidance, combined with the development of systems and processes to optimise the entry of new medicines and ensure financial sustainability, whilst also continuing to encourage innovation and research into new treatments in areas of greatest clinical unmet need. ' Fundamental changes in healthcare systems and industry will be needed to sustain cancer care and allow continued, and conceivably expanded, access to effective and safe treatments for all patients. 
In addition, there is a need for evidence-based treatment guidelines that examine QoL and survival data and assess benefit in relation to cost, to provide the cost utility of cancer drugs, and help physicians and patients make better informed treatment decisions. There must be a balance between physician autonomy in prescribing and costs incurred by society. ${ }^{30} \mathrm{~A}$ multidisciplinary approach to decision-making is also needed, involving hospital pharmacists and other team members, together with education to encourage healthcare providers to selectively accept new and/or costly cancer treatments.

A substantial proportion of the global cancer burden sits within lowand middle-income countries where the cancer care infrastructure is often poor. In these resource-constrained settings, selecting medicines that are affordable and offer value is particularly challenging. The aim of the World Health Organization Model Essential Medicines List is to improve access to innovative medicines that show clear clinical benefits. ${ }^{62}$ The list helps countries to prioritise effective drugs, and serves as a guide for the development of national and institutional essential medicine lists. Each drug on the list has been assessed for efficacy, safety and quality, and a comparative costeffectiveness evaluation has been performed with other alternatives in the same class. This list currently contains 46 approved treatments for 26 different types of cancer. ${ }^{63}$

\section{Conclusion}

We believe that there is a crisis of affordability in oncology that is not sustainable, and is not being adequately addressed. The future economic burden of cancer is closely linked to rising cancer incidence and increased survival, alongside greater investment in disease prevention, diagnosis and treatment. Despite advances in our understanding of cancer biology, and the advent of new technology and faster drug development schemes, there has been no reduction in the rising cost of commercial drug development, and the price of new drugs continues to increase as pharmaceutical companies strive to achieve greater innovation with new treatments.

There are only limited options for future health spending. The affordability of newly developed cancer medicines is not sustainable and new solutions to ensure rapid and equitable access to treatment must be found, whilst also safeguarding the continued development of new and effective treatments. Sustainable cancer care and continued, and conceivably expanded, access to effective and safe treatments for all patients will require fundamental changes in healthcare systems and industry.

Public health systems will need to make well-informed choices in order to distribute limited resources in the most efficient way. Currently, too many cancer drugs are being approved for use without robust evidence of good value for scarce resources, and clearer HTA-based guidance is required. For new medicines, in addition to efficacy and safety, there should be a focus on value with measured outcomes (e.g., overall survival), with pricing that makes these drugs affordable for all. A shift is needed towards a multidisciplinary approach to decision-making, which includes hospital pharmacists and other team members, to ensure that from a societal perspective, the most appropriate treatment decisions are made. Education is also required to encourage healthcare providers to accept selectively new and/or costly cancer treatments.

Spending more on cancer drugs does not necessarily translate to improvements in health, and higher costs of treatment should only be considered acceptable if improved patient outcomes can be demonstrated. A balance must also be found between healthcare affordability and profit, to provide the necessary incentives for pharmaceutical manufacturers to ensure continued innovation. We need both a sustainable healthcare system and a sustainable model for drug development. The model that can sustain cancer care can be considered a template for other areas of medicine.
1. World Health Organization. Access to new medicines in Europe: technical review of policy initiatives and opportunities for collaboration and research (2015). Available at: wwweuro who int/en/health-topics/Health-systems/health-technologies-andmedicines/publications/2015/access-to-new-medicines-in-

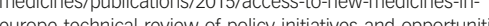
europe-technical-review-of-policy-initiatives-and-opportunitiesfor-collaboration-andescich 2015 (accessed 11 August 2017).

Jonsson B, Hormarcher T, Lindgren r, Wiking N, Comparator report on patient access to cancer medicines in Europe revisited (2016). Avallable at. http://ihe.se/en/publicering/ cancer-medicines-in-europe-2 (accessed 11 August 2017).

3. Cole A, Lundqvist A, Lorgelly P, et al., Improving efficiency and resource allocation in future cancer care (2016). Available at: www.ohe.org/publications/improving-efficiency-and-resourceallocation-future-cancer-care (accessed 11 August 2017).

4. GBD 2013 DALYS and HALE Collaborators, Murray CJL, Barber RM, et al., Global, regional, and national disability-adjusted life years (DALYS) for 306 diseases and injuries and healthy life expectancy (HALE) for 188 countries, 1990-2013: quantifying the epidemiological transition, Lancet, 2015;386:2145-91.

5. Ferlay J, Steliarova-Foucher E, Lortet-Tieulent J, et al., Cancer incidence and mortality patterns in Europe: estimates for 40 incidence and mortality patterns in Europe: estimates f

6. van Harten WH, Wind A, de Paoli P, et al., Actual costs of cancer drugs in 15 European countries, Lancet Oncol, 2016;17:18-20. Schrag D, The price tag on progress-chemotherapy for colorectal cancer, N Engl J Med, 2004;351:317-9.

8. Bach PB, Limits on Medicare's ability to control rising spending on cancer drugs, N Eng/ J Med, 2009;360:626-33.

. Lichtenberg FR, The expanding pharmaceutical arsenal in the war on cancer: NBER Working Paper No. 10328 (2004). Available at: www.nber.org/papers/w10328 (accessed 11 August 2017).

10. Rajkumar SV, Harousseau JL, Next-generation multiple myeloma treatment: a pharmacoeconomic perspective, Blood 2016;128:2757-64

11. Debiasi M, Reinert T, Kaliks R, et al., Estimation of premature deaths from lack of access to anti-HER2 therapy for advanced breast cancer in the Brazilian public health system, Journal of Global Oncology, 2017:3:201-7.

12. Miller JD, Foley KA, Russell MW, Current challenges in health economic modeling of cancer therapies: a research inquiry, Am Health Drug Benefits, 2014;7:153-62.

13. Simoens $S$, van Harten W, Lopes $G$, et al., What happens when the cost of cancer care becomes unsustainable?, European
Oncology and Haematology, 2017;13:ePub.

14. Jonsson B, Hofmarcher T, Lindgren $P$, et al., The cost and burden of cancer in the European Union 1995-2014, Eur J Cancer 2016;66:162-70.

15. Shulman $L N$, The effect of accountable care organizations on oncology practice, Am Soc Clin Oncol Educ Book, 2014:e468-71.

16. Quintiles IMS, Global oncology trend report. A review of 2015 and outlook to 2020. Available at: http://www.imshealth.com/ and outlook to 2020. Available at: http://Mww.imshealth.com/
en/thought-leadership/quintilesims-institute/reports/globalen/thought-leadership/quintilesims-institute/reports/global-
oncology-trend-report-a-review-of-2015-and-outlook-to-2020 oncology-trend-report-a-revi
(accessed 11 August 2017).

17. Cornes $P$, The economic pressures for biosimilar drug use in cancer medicine, Target Oncol, 2012;7:57-67.

18. Shih $\mathrm{YC}$, Hurria A, Preparing for an epidemic: Cancer care in an aging population, Am Soc Clin Oncol Educ Book, 2014:133-7. 19. Mullard A, 2014 FDA drug approvals, Nat Rev Drug Discov, 2015;14:77-81.

20. Mullard A, 2015 FDA drug approvals, Nat Rev Drug Discov, 2016;15:73-6.

21. Mullard A, 2016 FDA drug approvals, Nat Rev Drug Discov, 2017;16:73-6.

22. Dusetzina $S B$, Muluneh $B$, Khan $T$, et al, obstacles to affordable cancer treatments, N C Med I, 2014;75:257-60.

23. Experts in Chronic Myeloid Leukemia, The price of drugs for chronic myeloid leukemia (CML) is a reflection of the unsustainable prices of cancer drugs: from the perspective of a large group of CML experts, Blood, 2013;121:4439-42.

24. Pfister DG, The Just Price of cancer drugs and the growing cost of cancer care: oncologists need to be part of the solution, J Clin Oncol, 2013;31:3487-9.

25. Avorn J, The $\$ 2.6$ billion pill? Methodologic and Policy Considerations, N Eng/ J Med, 2015;372:1877-9.

26. Light $D W$, Warburton $R$, Demythologizing the high costs of pharmaceutical research, Biosocieties, 2011;6:34-50.

27. Mazzucato $\mathrm{M}$, The Entrepreneurial State. Debunking public vs private sector myths, 2013. Available from: www.looooker. com/wp-content/uploads/2015/05/The-Entrepreneurial-statecom/wp-content/uploads/2015/05/The-Entrepreneurial-StateAugust 2017).

28. Mailankody S, Prasad V, Five years of cancer drug approvals. innovation, efficacy, and costs, JAMA Oncol, 2015;1:539-40.

29. Gozzo L, Navarria A, Drago V, et al., Linking the price of cance drug treatments to their clinical value, Clin Drug Investig,
2016;36:579-89

30. Siddiqui M, Rajkumar SV, The high cost of cancer drugs and what we can do about it, Mayo Clin Proc, 2012;87:935-43.

31. Venkatesan S, Lamfers M, Leenstra S, et al., Overview of the patent expiry of (non-)tyrosine kinase inhibitors approved for clinical use in the EU and the US, GaBI Journal, 2017;6:89-96.

32 Wirtz VI, Hogerzeil HV, Gray AL, et aL Essential medicines for universal health coverage, Lancet, 2017:389:403-76.

33. Love J, Rius J, Contribution to the United Nations SecretaryGeneral's high level panel on access to medicines: the need for global negotiations on agreements to fund R\&D within the context of a progressive de-linking of R\&D costs from product prices, 2016. Available from: www.unsgaccessmeds.org/ inbox/2016/2/29/james-love (accessed 11 August 2017).

34. Report of the United Nations Secretary General's High-Level Panel On Access To Medicines, 2016 Available from: www. unsgaccessmeds.org/s/UNSG-HLP-Report-FINAL-12-Sept-2016. pdf (accessed 11 August 2017)

35. Consultative Expert Working Group on Research and Development: financing and coordination, Research and development to meet health needs in developing countries: Strengthening global financing and coordination, 2012. Available from: www who.int/phi/CEWG_Report_5_April_2012. Available from: www. Who. Int/ph
pdf (accessed 11 August 2017)

36. Seventieth World Health Assembly, Cancer prevention and control in the context of an integrated approach. Draft resolution proposed by Brazil, Canada, Colombia, Costa Rica, France, Netherlands, Nigeria, Panama, Peru, Russian Federation, Thailand and Zambia, 2017. Available from: http:// apps.who.int/gb/ebwha/pdf_files/WHA70/A70_ACONF9-en.pdf (accessed 11 August 2017)

37. Forster $R$, Pharmaceutical giant 'plotted to destroy cancer drugs to drive prices up 4,000\%', 2017. Available at: www. independent.co.uk/news/health/drug-giant-aspen-plot-destroycancer-medicine-big-pharma-times-investigation-a7683521. html (accessed 11 August 2017)

38. Giannuzzi V, Conte R, Landi A, et al., Orphan medicinal products in Europe and United States to cover needs of patients with rare diseases: an increased common effort is to be foreseen, Orphanet I Rare Dis, 2017;12:64.

39. Kesselheim AS, Treasure CL, Joffe S, Biomarker-defined subsets of common diseases: policy and economic implications of Orphan Drug Act coverage, PLOS Med, 2017;14:e1002190. 40. Quintiles IMS Institute, Ensuring essential medicines satisfy 
priority healthcare needs of populations. Evolution, current state and future needs, 2016. Available at: www. ifpma org/ wp-content/uploads/2016/11/2016-QuintilesIMS pdf (accessed 11 August 2017)

41. Danzon PM, Taylor $E$, Drug pricing and value in oncology, Oncologist, 2010;15 Suppl 1:24-31.

42. Vogler S, Vitry A, Babar ZU, Cancer drugs in 16 European countries, Australia, and New Zealand: a cross-country price comparison study, Lancet Oncol, 2016;17:39-47.

43. Navarria A, Drago V, Gozzo L, et al., Do the current performance-based schemes in Italy really work? "Success Fee": a novel measure for cost-containment of drug expenditure, Value In Health, 2015;18:131-6.

44. Carlson JJ, Sullivan SD, Garrison LP, et al., Linking payment to health outcomes: a taxonomy and examination of performance-based reimbursement schemes between healthcare payers and manufacturers, HealthPol, 2010;96:179-90

45. Afghahi A, Sledge GW, Jr., Targeted therapy for cancer in the genomic era, Cancer J, 2015;21:294-8.

46. Munoz J, Kurzrock R, Targeted therapy in rare cancers adopting the orphans, Nat Rev Clin Oncol, 2012:9:631-42.

47. Sullivan R, Peppercorn J, Sikora K, et al., Delivering affordable cancer care in high-income countries, Lancet Oncol, 2011;12:933-80

48. Kanavos $P$, Schurer $W$, The dynamics of colorectal cancer management in 17 countries, Eur J Health Econ, 2010;10 Suppl 1:S115-29.

49. Sullivan R, Cancerworld, Affordable cancer care: a global mirage?, 2016. Available at: http://cancerworld.net/our-world/ affordable-cancer-care-a-global-mirage/ (accessed 11 August 2017).

50. Sleijfer $\mathrm{S}$, Verweij J, Health policy: affordability of drugs used in oncology health care, Nat Rev Clin Oncol, 2016;13:331-2.

51. New drugs, new indications in 2015: Little progress, and threats to access to quality healthcare for all, Prescrire Int, 2016;25:139-9

52. Guirgis HM, Proposal for a novel methodology to screen and score cost versus survival for anticancer drugs in metastatic disease: could cost weigh in evaluation, J Oncol Pract, 2012;8:224-30.

53. Porter ME, What is value in health care?, N Eng/ $\mathrm{J}$ Med 2010:363:2477-81

54. Goulart $\mathrm{BH}$, Value: the next frontier in cancer care, Oncologist, 2016;21:651-3.

55. Kang R, Goodney PP, Wong SL, Importance of cost-effectiveness and value in cancer care and healthcare policy, I Surg Oncol, 2016:114:275-80.

56. Cherny NI, Sullivan R, Dafni U, et al., A standardised, generic, validated approach to stratify the magnitude of clinical benefit validated approach to stratify the magnitude of clinical be
that can be anticipated from anti-cancer therapies: the that can be anticipated from anti-cancer therapies: the
European Society for Medical Oncology Magnitude of Clinical
Benefit Scale (ESMO-MCBS), Ann Oncol, 2015;26:1547-73.

57. Schnipper LE, Davidson NE, Wollins DS, et al., Updating the American Society of Clinical Oncology Value Framework: Revisions and Reflections in Response to Comments Received, J Clin Oncol, 2016;34:2925-34.

58. Ellis LM, Bernstein DS, Voest EE, et al American Society of Clinical Oncology perspective: raising the bar for clinical trials by defining clinically meaningful outcomes, J Clin Oncol 2014;32:1277-80

59. Saez C, New W, Stakeholders take 'first step' on fair pricing for medicines, 2017. Available from: http://catalyst.nejm. org/a-new-way-to-define-value-in-drug-pricing (accessed 11 August 2017).

60. Bach PB, A new way to define value in drug pricing, 2016. Available from: http://catalyst.nejm.org/a-new-way-to-definevalue-in-drug-pricing/ (accessed 11 August 2017)

61. Nadler E, Eckert B, Neumann PJ, Do oncologists believe new cancer drugs offer good value?, Oncologist, 2006:11:90-5.

62. World Health Organization, 19th WHO Model List of Essential Medicines - 19th List, April 2015; amended November 2015. Available at: http://www.who.int/medicines/publications/ Available at: http://Www. Who.Int/medicines/publications/ essentialmedicines/EML_2015_FINAL_-
pdf?ua=1 (accessed 11 August 2017).

63. Shulman $L N$, Wagner CM, Barr R, et al., Proposing essentia Shulman $\mathrm{LN}$, Wagner $\mathrm{CM}$, Barr R, et al., Proposing essential
medicines to treat cancer: methodologies, processes, and outcomes, I Clin Oncol, 2016;34:69-75. 